Tarih Kültür ve Sanat Araştırmaları Dergisi

Revue des Recherches en Histoire Culture et Art

مجلة البحوث التاريخية والثقافية والفنية
Vol. 6, No. 6, December 2017

Copyright (C) Karabuk University

http://kutaksam.karabuk.edu.tr

\title{
DOI: 10.7596/taksad.v6i6.1105
}

Citation: Namin, H. S. (2017). Presenting a Model for Setting in Narrative Fiction Illustration. Journal of History Culture and Art Research, 6(6), 73-83. doi:http://dx.doi.org/10.7596/taksad.v6i6.1105

\section{Presenting a Model for Setting in Narrative Fiction Illustration}

Hajar Salimi Namin ${ }^{1}$

\begin{abstract}
The present research aims at presenting a model for evaluating and enhancing training the setting in illustration for narrative fictions for undergraduate students of graphic design who are weak in setting. The research utilized expert's opinions through a survey. The designed model was submitted to eight experts, and their opinions were used to have the model adjusted and improved. Used as research instruments were notes, materials in text books, papers, and related websites, as well as questionnaires. Results indicated that, for evaluating and enhancing the level of training the setting in illustration for narrative fiction to students, one needs to extract sub-indexes of setting. Moreover, definition and recognition of the model of setting helps undergraduate students of graphic design enhance the level of setting in their works skill by recognizing details of setting. Accordingly, it is recommended to design training packages to enhance these sub-indexes and hence improve the setting for narrative fiction illustration.
\end{abstract}

Keywords: Illustration, Illustration for barrative fiction, Setting, Time and location, Literal setting, Conceptual setting.

\footnotetext{
${ }^{1}$ Faculty Member, School of Art, Al-Zahra University. E-mail: hajar_salimi@yahoo.com
} 


\section{Introduction}

The present research is the result of educating narrative fiction illustration to undergraduate students of graphic design. In students' art works within the scope of setting, the issue of inability to create appropriate setting in illustration for narrative fictions is well exposed. In other words, when it comes to setting, students either just fail to use appropriate locative and temporal factors to set the fiction space, or use these factors inappropriately or inadequately; i.e. they present inappropriate setting.

In the modern world of today, the subject matter of illustration has been increasingly regarded by illustrators, publishers, audience, etc. This is while Iranian illustrators either neglect to present any setting in their art works or just copy those originally created by non-Iranian illustrators.

Investigations have revealed that, the lack of recognition of the sub-indexes of the setting is the general cause of an improper setting by undergraduate students of graphic design. As such, generally speaking, the present research looks forward to answer the following question:

\section{What are sub-indexes of setting for narrative fiction illustration?}

Investigating various references, no model was found for the evaluation of setting for the illustration of narrative fiction. In the field of engineering design, ideas or solutions are defined as the results and outputs of solving design problems. Therefore, ideas or proposals are the output of a design process respect to the design problem or task by a design team. To assess design process, first, the characteristics of required design proposals and ideas are defined.

Some common criteria for assessing the generated ideas and design proposals are discussed in the literature. In most research, the group performance is defined by evaluating the proposals regarding the number of ideas (Nijstad et al., 2002; Shah et al., 2003; Perttula and Sipila, 2007) and quality of ideas (Wierenga, 1998; Shah et al., 2003). Consequently, the quality of an idea is determined by appropriateness and originality on the target task (Massetti, 1996; Runco and Jaeger, 2012) and some situations unexpectedness (Gero, 1996) and Non-obviousness (Howard et al., 2006 and 2008). Some examinations in engineering characterize these criteria by the level of meeting goals (Shah et al., 2003).

However, such a model was not found in the literature of illustration. Therefore, the main objective of the present research is to propose a model for evaluating and improving training in setting for the illustration of narrative fictions for undergraduate students of graphic design who are weak in setting appropriately.

To this end, as a first step, available information in the literature were investigated via library studies, and an initial model was developed by considering sub-indexes of setting. Afterwards, a questionnaire was prepared on the proposed model and distributed among eight experts in the field of illustration. Once the questionnaire was collected, a final model was designed according to their opinions.

In Section 1 a review is given on basic concepts of illustration, narrative fiction illustration, and setting followed by presenting a background for the research. Section 2 delivers the research 
question and methodology. In Section 3, the research results are reported, followed by discussion, conclusion and some recommendations.

\section{Literature review}

\subsection{Basic concepts}

\section{Illustration}

Illustration is not solely an art or graphic design. As a discipline, illustration sits somewhere between art and graphic design. Of course, for many practitioners it can feel closer to end of this spectrum than the other (Zeegen, 2009: 6). However, there is a distinct core that is unlike anything else and it is this that defines its 'raison d'être'. Alan Male defines illustration as; "Illustration is about communicating a specific contextualized message to an audience. It is rooted in an objective need, which has either been generated by the illustrator or a commercial based client to fulfill a particular task. It is the measure and variety of these different tasks that makes the discipline of illustration such an influential visual language" (2007:10).

Today, illustration is no more worried about its distance to pure art, and this is an issue we were not face 30 years ago, and the number of pure arts further resembling illustration is ever increasing (Wiedemann, 2009: 10-11).

\section{Illustration for narrative fiction}

Storytelling is often considered a prerequisite to provide visual representation of narrative fiction. Today, narrative fictional illustration is mainly encountered in children's books, graphic novels and comic strips, and specialist publications such as thematic compilations, containing mythology, gothic tales and fantasy (Male, 2007: 138).

The factors of illustration for narrative fiction are character, plot, setting, theme, style, structure, form, genre, narration, tense and other related like audience, author, idea, creativity, imagination, fiction writing, storytelling, storyboard, technique, drawing, composition, color, space, book cover, layout, ... but essential one's are idea, character, setting, storyboard, composition, technique and color.

\section{Setting}

The setting includes both the time and geographic location within an illustration for narrative fiction. Along with the plot, character, theme, and style, setting is considered one of the fundamental components of fiction (Maass, 2015). Setting is an important element in a narrative and in some works the setting becomes a character itself (Ibid). Recently, setting has gained larger deals of attention and focused from illustrators, making it introduced into a new stage of growth, maturity, and diversification. 


\subsection{Research background}

Illustration: A Theoretical \& Contextual Perspective (2007) presents a brief discussion on setting in a section entitled as Illustration for children's narrative fiction. Moreover, the title lllustrating Children's Books: Creating Pictures for Publication (2004) also provides a brief introduction on setting in a section entitled as Setting the scene. In the present research, these two titles are reviewed and investigated.

The itinerant illustration: Creating story worlds in the reader's space paper in Journal of Illustration in 2015 explores the storytelling potential of direct address within illustration. As such, considering its direct address potential in setting, this paper was investigated in the present research.

Despite the attempt made, no further book, paper or research activity was found where the subject matter of the present research was particularly discussed. That is to say, the identification of the subindexes of the setting in the illustration of narrative fictions seems to be a new topic in art studies throughout the world.

\section{Research methodology}

\subsection{Research question}

What are sub-indexes of setting for narrative fiction illustration?

\subsection{Data collection method}

Research terms, concepts, and literature were collected by investigating available material on virtual and physical spaces in combination with such methods as text-reading, note-taking, and picturereading, and the model structure was developed based on field surveys.

\subsection{Data collection instrument}

In the present research, notes, materials published in text books, papers, journals, and related websites, and also questionnaires were used to collect the required data.

\subsection{Research method}

1. As a first step, based on practical experience of illustration and training illustration courses by the researcher, lack of recognition of sub-indexes of setting in narrative fiction illustration was identified as the root cause of the problem of improper setting by the students. As such, library resources were used to extract different indexes related to setting.

- The setting includes both the time and geographic location within a narrative or within a work of fiction (Maass, 2015), (see Table 1). 
Table 1. Setting (Source: Maass, 2015).

\begin{tabular}{|l|l|}
\hline \multirow{3}{*}{ Setting } & 1. Location \\
\cline { 2 - 2 } & 2. Time \\
\hline
\end{tabular}

- Every character must be conceived from painstaking observations of body language, gesture, expression, movement, individual idiosyncrasy and eccentricity. Personality, trait and emotion must also be convincingly portrayed. Mood and sense of being can be presented by an appropriate representation of physical gait, hands and facial expression (Male, 2007: 154), (see Table 2).

Table 2. Character creation (Source: Male, 2007: 154).

\begin{tabular}{|l|l|}
\hline \multirow{3}{*}{ Character creation } & 1. Creating character's appearance \\
\cline { 2 - 2 } & 2. Creating character's inner aspects \\
\hline
\end{tabular}

- In the best case, the setting becomes a character itself (Maass, 2015), (see Table 3).

Table 3. Setting (Source: Maass, 2015).

\begin{tabular}{|l|l|}
\hline \multirow{2}{*}{ Setting } & 1. Setting's appearance \\
\cline { 2 - 2 } & 2. Setting's inner aspects \\
\hline
\end{tabular}

- A historical and contemporary overview of illustration will depict seemingly hundreds of styles. However, there are just two forms of imagery. All variations of visual language will be placed within one of these. Literal illustrations tend to represent pictorial truths. The second form of illustration can be described as conceptual (Male, 2007: 50), (see Table 5, 6).

Table 5. Location

\begin{tabular}{|l|l|}
\hline \multirow{2}{*}{ Location } & 1. Conceptual location \\
\cline { 2 - 2 } & 2. Literal location \\
\hline
\end{tabular}

Table 6. Time

\begin{tabular}{|l|l|}
\hline \multirow{2}{*}{ Time } & 1. Conceptual time \\
\cline { 2 - 2 } & 2. Literal time \\
\hline
\end{tabular}

- Afterwards, the researcher proceeded to design sub-indexes of setting in narrative fiction illustration based on the above indexes, as follows (Table 7): 
Table 7. sub-indexes of setting in narrative fiction illustration

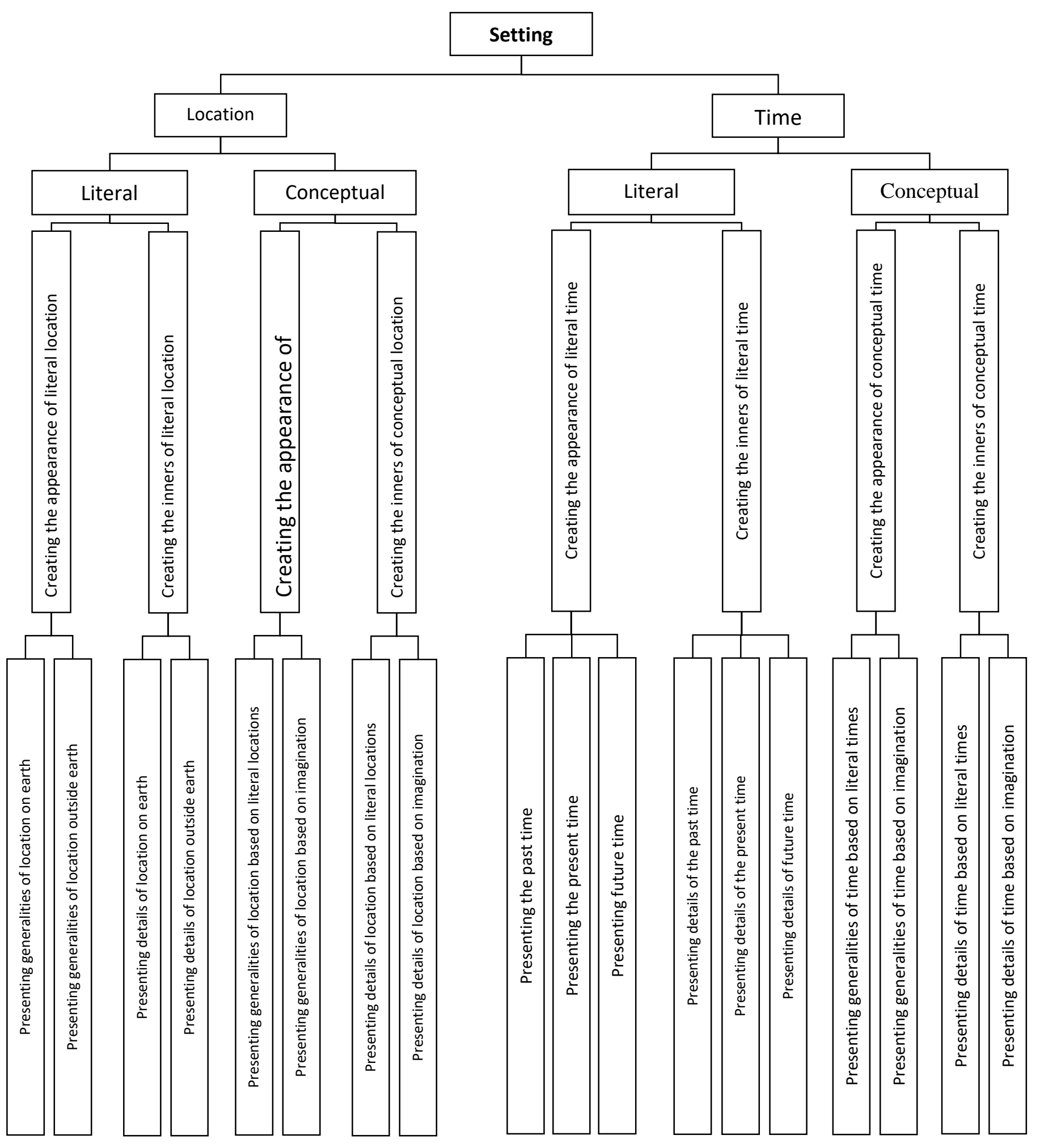




\section{Observations and results}

3.1. A questionnaire themed by the proposed model was developed using structured method with "close-ended" questions. It was then submitted to eight Iranian experts in the field of illustration. Mostafa Goudarzi, Morteza Esmaeili Sohi, Effat-al-Sadat Afzal Toosi, Mohsen Hasanpoor, Mohammad Reza Doost Mohammadi, Khashayar Ghazi Zadeh, Mehran Kashti Ara, and Mohammad Ali Bani Asadi were the experts participated in this research. They were selected based on their educations (MA and $\mathrm{PhD}$ ) and teaching experiences in illustration. At the end of the questionnaire, the experts were asked to mention any index other than those incorporated into the model, if necessary (Table 8).

Table 8. The questionnaire submitted to the experts.

\begin{tabular}{|c|c|c|c|c|}
\hline Sub & ind & lexes of $\mathrm{pr}$ & er setting for illt & tion of narrative fictions \\
\hline & & & Cronting the pnomenes & 1. Presenting generalities of location on earth \\
\hline & & & Creating the appearance & 2. Presenting generalities of location outside earth \\
\hline & & LIteral & Creating the innere & 1. Presenting details of location on earth \\
\hline & & & Creating the inners & 2. Presenting details of location outside earth \\
\hline & & & Creating the annearance & 1. Presenting generalities of location based on literal locations \\
\hline & $\subsetneq$ & & Creating the dppedrance & 2. Presenting generalities of location based on imagination \\
\hline & 苞 & mal & Creating the inners & 1. Presenting details of location based on literal locations \\
\hline & & & Credung tre intrers & 2. Presenting details of location based on imagination \\
\hline & & & & 1. Presenting the past time \\
\hline & & & Creating the appearance & 2. Presenting the present time \\
\hline & & & & 3. Presenting future time \\
\hline & & Literal & & 1. Presenting details of the past time \\
\hline & & & Creating the inners & 2. Presenting details of the present time \\
\hline & & & & 3. Presenting details of future time \\
\hline & & & Creating the annearance & 1. Presenting generalities of time based on literal times \\
\hline. & & Concept & Creating the appearance & 2. Presenting generalities of time based on imagination \\
\hline 全 & $\stackrel{\varrho}{\xi}$ & & Creating the innerc & 1. Presenting details of time based on literal times \\
\hline$=$ & $j$ & & Creatıng the inners & 2. Presenting details of time based on imagination \\
\hline
\end{tabular}

3.2. The experts' responses to each of the sub-indexes mentioned in the model are presented in Table 9. 
Table 9. Summary of the experts' opinions.

Sub-indexes of proper setting for illustration of narrative fictions

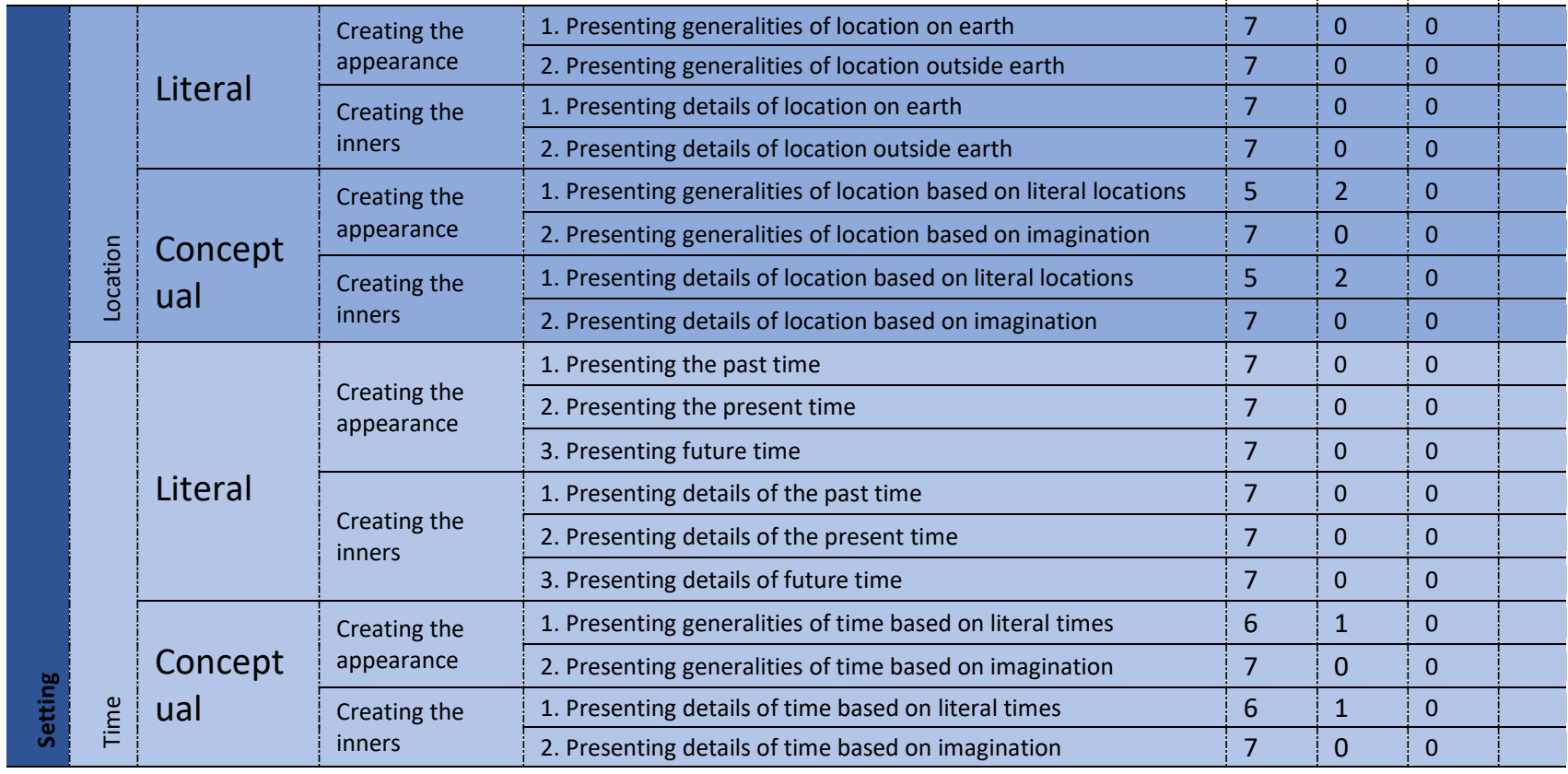

3.3. In addition to the "close-ended" questions in the questionnaire, the experts gave some recommendations toward enhancing and improving the model, as follows.

Therefore, based on the recommendations, the following items were modified accordingly:

- presenting generalities of location on earth and outside earth converted to presenting generalities of urban, rural and natural locations.

- presenting details of location on earth and outside earth converted to presenting details of urban, rural and natural locations.

3.4. Once the questionnaires were collected and the experts' responses were processed, the model was modified and improved according to their opinions, and the final model was designed (Table 10). 
Table 10. Model of effective sub-indexes of proper setting for illustration of narrative fictions.

\section{Sub-indexes of proper setting for illustration of narrative fictions}

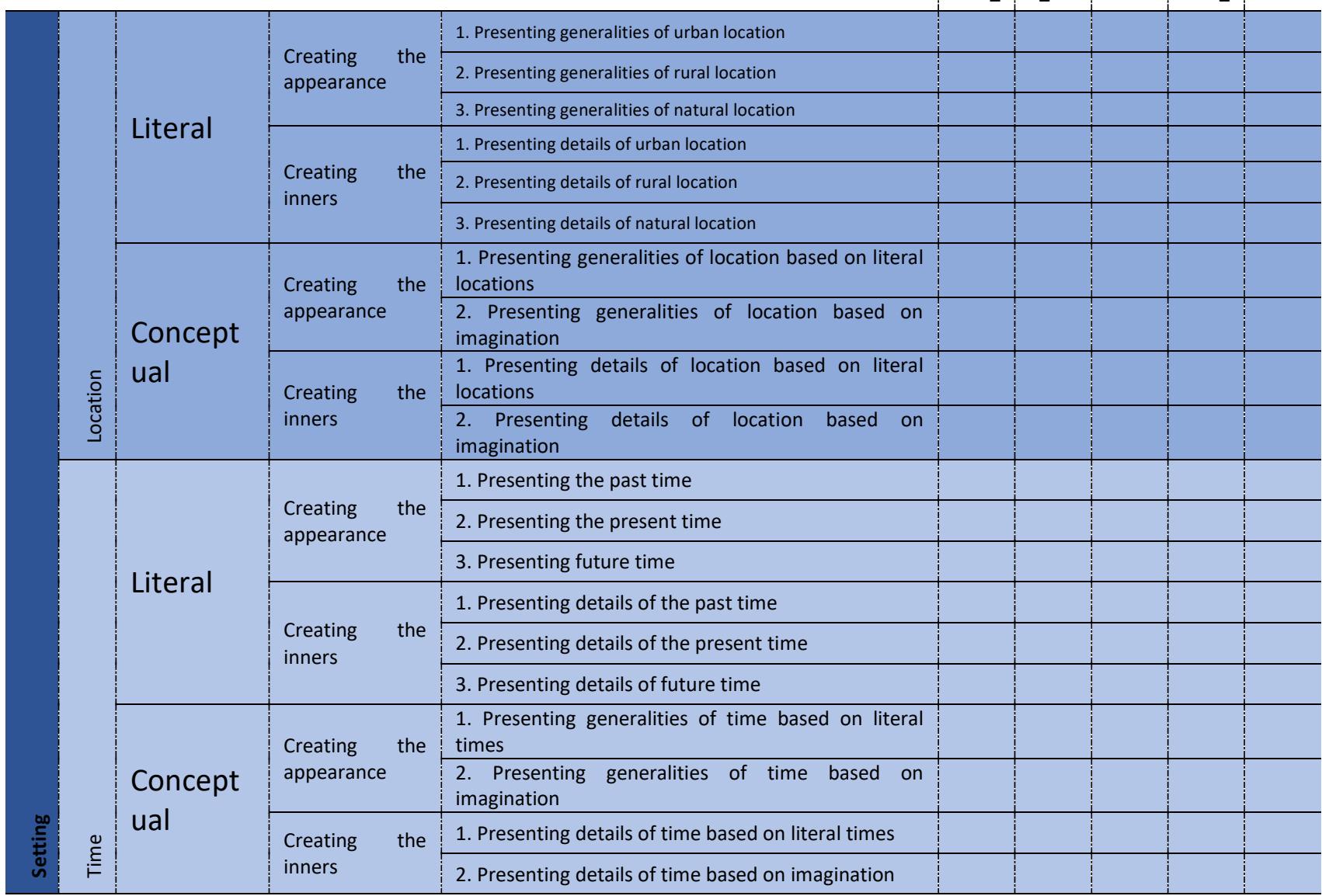

- Creation the appearance of a literal location means creating generalities of an urban, rural or natural location. For instance, for the first case, generalities of a house in Tehran, for the second case, generalities of a cottage in a forest, and for the third case the view of a mountain can be mentioned.

- Creation the inners (i.e. spirit) of a literal location means presenting credible details of an urban, rural or natural location. For instance, for the first case, presenting credible details about people's life in the house in Tehran (e.g. the curtains, the wicks, the garden, and the bicycle in the yard); for the second case, the details about the life in the cottage and for the last case, some credible details about the tents of the mountain climbers which can show the life in mountains.

- Creation the appearance of conceptual location means creating generalities of a conceptual location based on either literal locations or imagination. Generalities of a gable-roofed house in desert and those of a house in heaven are examples of the former and latter cases, respectively.

- Creation the inners of conceptual location means presenting believable details of conceptual location based on either literal locations or imagination. Presenting believable details on the life at the gable-roofed house and those on the life in the house in heaven (e.g. trees, flowers, and springs passing through the garden) are examples of the former and latter cases, respectively. 
- Creation the appearance of literal time means creating generalities of past, present, or future time. A night in the last winter, today morning, and an afternoon in the next fall are examples of the three cases, respectively.

- Creation the inners (i.e. spirit) of literal time means presenting believable details of past, present, or future time. Moon and stars at night, rising sun, and clouds in the raining sky are examples of the three cases, respectively.

- Creation the appearance of conceptual time means creating generalities of an conceptual time based on either literal times or imagination. Presenting a situation where sun and moon are seen on the sky simultaneously and describing a day in heaven are examples of the former and latter cases, respectively.

- Creation the inners of conceptual time means presenting believable details of conceptual time based on either literal times or imagination. Presenting believable details like sun and moon in a light-blue sky full of stars and those on a day in heaven like fruits of all seasons on trees are examples of the former and latter cases, respectively.

\section{Discussion and conclusion}

The present research was performed aiming at presenting a model for evaluating and enhancing the training on setting in illustration for narrative fictions for undergraduate students of graphic design who are weak in setting. For this purpose, sub-indexes of setting in narrative fiction illustration were identified. Elaborating on this finding, the followings can be stipulated:

- For evaluating and enhancing the level of training the setting in illustration for narrative fictions to students, one needs to extract sub-indexes of setting.

- Definition and recognition of the model of setting helps undergraduate students of graphic design enhance the level of setting in their works skill by recognizing details of setting.

- Generally, four types of setting may exist:

1. Literal location + Literal time $=$ Literal setting

2. Literal location + Conceptual time $=$ Conceptual setting

3. Conceptual location + Literal time $=$ Conceptual setting

4. Conceptual location + Conceptual time $=$ Conceptual setting

- Presenting generalities is needed for demonstrating the appearance of location and time, while believable details shall be presented to express inners and spirit of the location and time.

It is recommended that:

1. Considering the proposed model, training packages shall be designed and provided to the students. Effectiveness of these packages and efficiency of the model can define topics for future research.

2. Searching for more detailed sub-indexes can be a topic for future research. 


\section{References}

Braund, S. (2015). The itinerant illustration: Creating storyworlds in the reader's space. Journal of Illustration, 2(2), 267-285.

Gero, J. S. (1996). Creativity, emergence and evolution in design. Knowledge-Based Systems, 9(7), 435448.

Howard, T. J.; Culley, S. J. \& Dekoninck, E. (2006). Information as an input into the creative process. In DS 36: Proceedings DESIGN 2006, the 9th International Design Conference, Dubrovnik, Croatia.

Howard, T.; Culley, S. \& Dekoninck, E. (2008, January). Creative stimulation in conceptual design: An analysis of industrial case studies. In ASME 2008 International Design Engineering Technical Conferences and Computers and Information in Engineering Conference (pp. 161-170). American Society of Mechanical Engineers.

Maass, D. (2015). The Breakout Novelist: How to Craft Novels That Stand Out and Sell. Ohio: Writer's Digest Books.

Male, A. (2007). Illustration: A Theoretical \& Contextual Perspective. Switzerland: AVA Publishing SA.

Massetti, B. (1996). An empirical examination of the value of creativity support systems on idea generation. MIS quarterly, 83-97.

Nijstad, B. A.; Stroebe, W. \& Lodewijkx, H. F. (2002). Cognitive stimulation and interference in groups: Exposure effects in an idea generation task. Journal of experimental social psychology, 38(6), 535-544.

Perttula, M. \& Sipilä, P. (2007). The idea exposure paradigm in design idea generation. Journal of Engineering Design, 18(1), 93-102.

Runco, M. A. \& Jaeger, G. J. (2012). The standard definition of creativity. Creativity Research Journal, 24(1), 92-96.

Salisbury, M. (2004). Illustrating Children's Books: Creating Pictures for Publication. Allen \& Unwin.

Shah, J. J.; Smith, S. M. \& Vargas-Hernandez, N. (2003). Metrics for measuring ideation effectiveness. Design studies, 24(2), 111-134.

Wiedemann, J. (2009). Illustration Now. Translated by Hana Dabzad. Tehran: Aban-Ketab Publications.

Wierenga, B. \& Van Bruggen, G. H. (1998). The dependent variable in research into the effects of creativity support systems: Quality and Quantity of ideas. MIS quarterly, 81-87.

Zeegen, L. (2009). What is illustration? Switzerland: Roto Vision SA. 